\title{
Exploring Undergraduates' Learning Engagement via BYOD in the Blended Learning Classroom (EULEBYODBLC)
}

\author{
Wei He and Li Zhao
}

\begin{abstract}
The study explored the learning engagement of BYOD (Bring your own device) in a blended-learning classroom. In a blended learning environment, 51 undergraduates of the same class participated in two core courses. In Course A, as the experimental group, they brought their own devices to facilitate their learning, whereas in Course B, as the control group, they did not. The study compared the undergraduates' engagement in the two courses. The results of the learning behavior analysis on the learning platform system and interviews after the 16-week courses showed that BYOD in the classroom improved the undergraduates' engagement in the blended learning classroom. Finally, the study is suggested that instructors and researchers could design learning activities in the classroom with BYOD support to improve undergraduates' engagement.
\end{abstract}

Index Terms-Blended learning, undergraduate, bring your own device (BYOD), learning engagement.

\section{INTRODUCTION}

The use of mobile technology such as smartphones and tablets is deeply embedded in college life for Generation $\mathrm{Z}$ (students born between 1995 and 2010) [1]. Knowledge is spread more effectively in real situations, and as Bransford, Brown and Cooking (2000) [2] said, learning is easily affected by the situation in which it takes place. In traditional courses, students often carry smartphones, tablets and other equipment, and it is common for teachers to confiscate these devices to prevent the students from being distracted in class [3]. But student are digital natives who cannot live without mobile devices. A number of universities around the world, especially in the United States, have realized the positive impact mobile technologies can have on fostering learning and increasing students' involvement. Therefore, Bring Your Own Device (BYOD) has been incorporated into classroom instruction [4]. That is, participants are encouraged to bring and use their own portable computing devices as a "personalized learning hub" to support their reflective engagement [5]. BYOD is expected to be used widely in the mainstream of higher education as a prevailing e-learning initiative [6]-[8]. The information technology trend supports the application of BYOD, but few studies have considered

Manuscript received September 12, 2019; revised December 14, 2019. This work was supported in part by Social Science Fund of Jiangsu (No.19JYB017); Collaborative Innovation Center for Talent Cultivating Mode in Basic Education; and Priority Academic Program Development of Jiangsu Higher Education Institutions in China

The authors are with Nanjing Normal University, Nanjing, China (corresponding author: Li Zhao; e-mail: 1324122949@qq.com, 20190231@qq.com). how the use of their own devices affects students' engagement as a learning behavioral index and its importance to course design to promote students' learning performance [9]. Thus, in this study BYOD was adopted to explore its learning effect on engagement in a blended learning environment.

Given the advancements in web technology, blended learning integrates traditional face-to-face classroom instruction with online digital learning. Programs in this blended modality are increasingly being adopted in higher education institutions [10]. For instance, the new media alliance's higher education version "Horizon Report: 2017" predicted that "blended learning" as a recent trend in the development of higher education will become increasingly popular [7]. Under the concept of blended learning and mobile learning, BYOD is gradually appearing in classrooms and becoming an important way to optimize classroom teaching. In addition, attention has often been paid to the forms of blended learning and BYOD, but there is still a lack of research on how BYOD can be used to promote better learning experiences and to enhance engagement [11].

One of the most irritating things for teachers in the 21st century is lack of engagement from learners. Students' low motivation and lack of interest have become a hot topic among instructors [12]. However, most research on blended learning has been on models, strategies, practices and design [13]. Despite the existing studies, blended learning and BYOD could be better integrated [3]. For example, whether the application of BYOD in face-to-face classes would improve the learning effect has rarely been explored in blended learning. Whether the learning effect can be improved by applying BYOD in a blended learning classroom should therefore be further studied. To address this gap, this study performed a comparative analysis of two courses and investigated the learning engagement of BYOD in the blended learning classroom.

\section{LITERATURE REVIEW}

\section{A. $B Y O D$}

Bring Your Own Devices (BYOD) originated from workers bringing their own personal mobile devices to the workplace and using them to perform work tasks [14], [15]. Some foreign schools in the United States, Australia, New Zealand and other countries have started BYOD projects whereby instructors and students are encouraged to bring their own equipment to the classroom, and to carry out practical applications [16]. From a Dutch university 
investigated, Kobus, Rietveld, and Ommeren (2011) [17] found that $96 \%$ of students own at least one of mobile IT devices. Through a 1-year study on the project of "BYOD for seamless science inquiry" in a primary school in Hong Kong, students developed positive attitudes toward seamless science inquiry supported by their own mobile devices [18]. Sung, Chang, and Liu [19] found that mobile devices such as laptops, personal digital assistants, and mobile phones had great potential in both classrooms and outdoor learning. BYOD offers a suitable platform for mobile learning in universities and has become the most important digital entrance of mobile learning [20].

With BYOD, blended learning in the information age can always be "Internet + ". The teaching application of BYOD fits the constructivist learning theory to a certain extent. For students, blended learning is based on the conditions of the physical system, through the interaction among the various elements in the human system, to integrate the intelligent system [21]. According to the blended learning theory, BYOD promotes the transformation of teaching methods, students can use their own equipment to retrieve, transfer, share, process and evaluate information, and can easily carry out various kinds of learning activities such as autonomous learning, inquiry learning, research studies and collaborative learning [3]. Conclusively, the BYOD integration model in flipped classrooms makes it possible to seamlessly bridge pre-class and in-class activities and to effectively promote student learning [22]; but how BYOD could facilitate students' learning has not been popularly studied in Chinese higher education, thus, this issue was explored in this study.

\section{B. Blended Learning}

The Blended learning is an activity of combining traditional teaching activities (that is face-to-face teaching) and learning activities supported with technologies [23] which complement the advantages of the face-to-face teaching and online learning [24]. Blended learning courses have proved to be quite popular [25], and have been increasingly used in higher education in recent years [10], [26], [27]. Investigating student engagement in the blended learning environment could help instructors and administrators understand student learning behavior and assess the quality of teaching and learning [28]. The degree of students actively involved in blended learning environments greatly influences their academic achievement and the quality of education [29].

Most studies have found that mobile technologies and new methodologies have positive learning outcomes [30]-[32]. Blended learning making effective use of a few tools could achieve quality in teaching, learning and course management [33]. There is, however, a pressing need for technologies or methods to increase student engagement in blended learning. BYOD meets undergraduates' individual needs, as learners in digital classrooms in general can afford to procure and bring their own digital portable devices for campus learning, and are capable of manipulating the various functions of digital portable devices for multiple tasks [34], [35]. Blended learning also have been taken in higher education to advance classroom instruction [36]. However, seldom study have focused on the application of BYOD satisfying the needs of a blended learning environment in higher education, and then it was subjected to be explored in this study.

\section{Learning Engagement}

Engagement is an important concept in learning theory which reflects the attention of students in the learning process [37], [38]. Student engagement is widely recognized as an important influence on achievement and learning in higher education and as such is being widely theorized and researched [39]-[41]. For example, Schaeffer and Konetes (2010) [42] verified that improving learner engagement in courses positively impacts learning performance and student success. Kwon, Chung, and Mi (2018) [43] analyzed the online and classroom learning engagement in the blended learning environment. Avci and Ergun (2019) [44] studied students' engagement in online courses. Serrano, Maria, Elena, Alfonso, and Lalatsa (2019) [33] studied how to enhance student engagement through blended learning. Jolly (2019) [45] depicted the relationship between business students' online engagement and blended learning. From those studies, it can be seen that much of the focus of learning engagement study has been on online learning and blended learning.

In blended learning, engagement is divided into online engagement and classroom engagement. Classroom engagement is a direction that needs to be explored. Skinner and Belmont (1993) [46] divided the engagement of learners into two dimensions: behavior and emotion. This study focused on students' engagement at the behavior and emotion levels. The study measured undergraduates' behavior engagement in learning from two aspects: the number of visits to the platform and the amount of discussion in the learning process. At the emotion level, the study measured undergraduates' engagement motivation.

\section{Research Questions}

Blended learning in higher education could promote student engagement [36]. However, students' lack of class engagement is a hot topic among instructors [12]. With the popularity of mobile intelligent terminals, BYOD in the classroom is expected to become a popular instructional strategy. Whether the application of BYOD in face-to-face classes will improve the learning effect has rarely been explored in Chinese blended learning. To address the research gaps, the following research questions were addressed in this study:

1) Does BYOD in the blended learning classroom improve learning engagement?

2) Can applying BYOD in the classroom promote undergraduates to use their devices for learning outside the classroom?

\section{METHOD}

\section{A. Participants}

A total of 51 undergraduates from the same class participated in this study. They took two courses named A and B in the same semester. In Course A, as the experimental group, the participants brought their own devices to help 
them vote, discuss, share viewpoints, read the links of related resources, and carry out learning activities such as autonomous and collaborative learning. In contrast, in Course $\mathrm{B}$, as the control group, they were forbidden to bring their own devices to the classroom. Both courses, were core courses of the same major, took place in a blended learning environment. Both have been designed as online courses uploaded to the online course platform and have the same number of course credits.

\section{B. Procedure}

The experiment lasted for 16 weeks (one class a week) during a whole semester. The two courses were based on the problem-solving learning method. The learning procedure was divided into the before-class (online) part, the in-class (face-to-face) part and the after-class (online) part. In the in-class part, BYOD was applied to Course A but not to Course B. The other parts of Course A and Course B did not require BYOD. All the learning activities in the different stages of the study are described as follows and illustrated in Fig. 1.

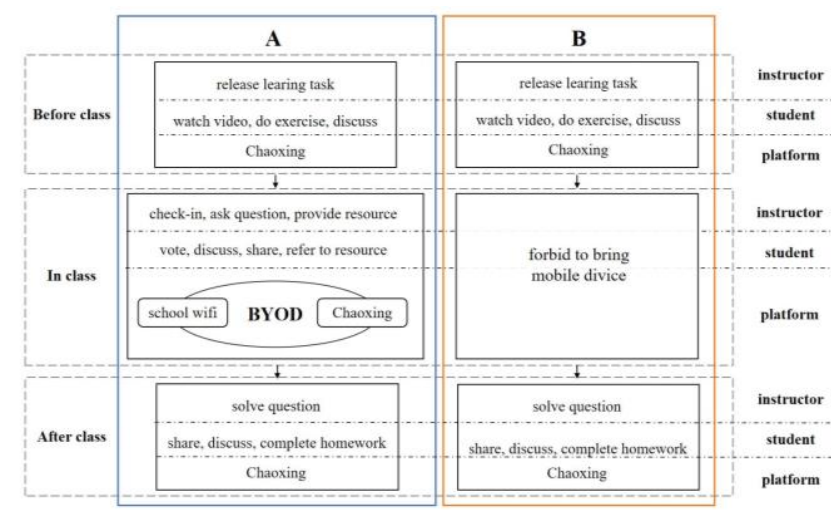

Fig. 1. Learning activities.

\section{1) Before class}

The instructor released learning tasks online through the Chaoxing learning platform, then the students learned the content through videos and presentations, and identified the difficulties related to their learning. They were divided into different groups. They could discuss their questions together or ask for help from group members or the instructor. The learning objective of this stage was to cultivate the abilities of self-learning, cooperation and communication.

\section{2) In class}

In the classroom, the control group was taught in a lecture-centered way. The instructor taught and explained the content and the students listened to the instructor carefully. In Course the students learned with the support of BYOD instruction. The Chaoxing learning platform included two interfaces, one for the instructor and another for students. At the beginning of Course A, the instructor and students logged into the Chaoxing learning platform through the instructor or student interface separately. Many learning activities including classroom management were carried out on the platform with the support of BYOD, such as students' check-in, asking questions, releasing tasks and providing resources. Meanwhile, the students applied BYOD in real-time voting, discussing, sharing viewpoints and reading the links of related resources of the course.

\section{3) After class}

After the class, the Chaoxing platform was used to distribute the coursework and other learning tasks. Students discussed and shared their learning experiences with classmates via the platform. They also needed to upload their coursework and check the comments from their classmates and the instructor. The platform could help students evaluate and enhance what they had learned.

\section{The Chaoxing Learning Platform As an Online Learning Platform}

Chaoxing was chosen as the BYOD learning platform for this study. Chaoxing is a professional online learning platform for mobile terminals such as smart phones and tablets. For undergraduates, it is easy-to-use education software based on mobile phones and computers. The Chaoxing learning platform provides advantages such as: a) convenient operation of the learning platform; b) publishing and receiving teaching information anytime and anywhere; c) supporting teachers and students to communicate anytime and anywhere; d) sharing high quality learning resources; and e) providing a learning analysis system to record students' learning behavior.

Both courses had an assistant to help the instructor on the online platform. All online visits and discussions were recorded on the Chaoxing learning platform. The discussions in the classroom were recorded on the platform discussion forum by the teaching assistant. Using the learning analysis system of the Chaoxing learning platform, the study extracted and collected the number of visits and the amount of discussion of the two courses, and then made a comparative analysis of the visits and discussion.

\section{Interview of Students' Engagement Motivation}

The students were divided into the same 12 groups in the two courses, and one student from each group were selected to take part in the interviews. Therefore, the one-on-one semi-structured interviews were conducted with 12 selected students. The aim of the interview was to explore students' engagement motivation when they applied BYOD in the blended learning classroom. Each interview lasted for $10 \mathrm{~min}$. Students were asked "Did BYOD to the classroom improve your motivations for learning engagement? If yes, please describe in what way."

\section{Data Analysis And Results}

The undergraduates' engagement was measured by how often students visited and took part in discussions. All of the data were collected by the Chaoxing learning platform. Details of the data collection are described as follows.

\section{A. The Number of Visits As Behavioral Engagement}

Up to the end of the courses, data were collected from the Chaoxing learning platform. According to the statistical results, the total number of visits to the platform for Course A was 18,895 compared with 9,496 for Course B. The platform recorded the number of times in the form of a line graph. Fig. 2 shows the number of times that the learners visited the 
learning platform in a month. It can be seen that there were significant differences in the number of visits, with the daily visits of Course A much more than those of Course B. The four dotted boxes represent the weekly visit situation; it can be seen that there was a peak of learning (the face-to-face classroom date) each week. Comparing the two courses, the highest daily number of Course A visits was up to 1,418 while that of Course B was only 456.

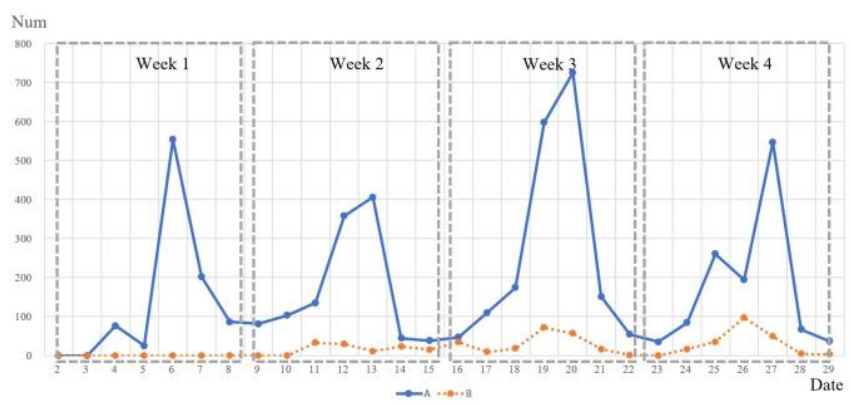

Fig. 2. The platform visits in September.

\section{B. Discussion As Behavioral Engagement}

The instructor of Course A issued a total of 16 online topics (one per week) on the platform, and the students' engagement in each online topic was very high, as shown in Fig. 3. On average, $98 \%$ of the students participated in the discussion for each topic. The highest percentage of participation was $167 \%$, which meant that many students participated in the topic two or more times. In the 16 topics, one student participated in the discussion 3.8 times on average. Especially on the day before the face-to-face class, students were the most active in the discussion among all the stages of discussion. However, only $26 \%$ of the students in Course B participated in the online platform discussion, and only three students were very active in the discussion throughout the whole semester. The average frequency of students' online discussion of Course B was 0.03 times per week.

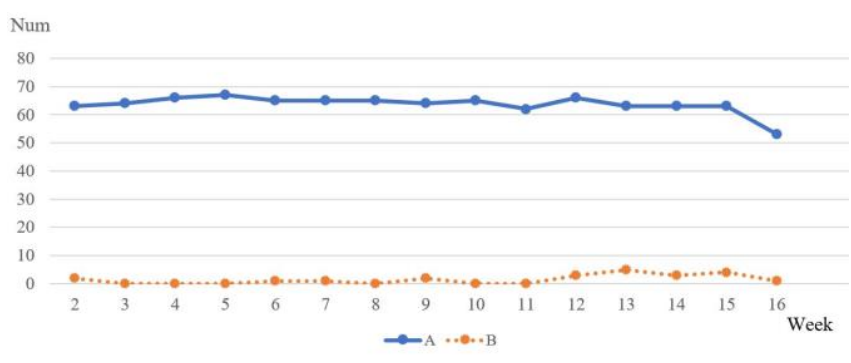

Fig. 3. The number of weekly platform discussions.

Fig. 4 shows the percentages of the students in Courses A and $\mathrm{B}$ who participated in the class discussions throughout the whole learning period. For Course A, with BYOD supporting the in-class learning activities, $100 \%$ of the students participated in class discussions throughout the whole learning period. For Course B, $26 \%$ of the students participated in the before-class and after-class discussion, and $40 \%$ participated in the in-class discussion.

\section{Motivation of Emotion Engagement}

In the interview, most of the students indicated that they would like to engage in Course A because, with BYOD, it was easy to access the information and learning. Through working in groups using their own devices, using the mobile devices and the Internet created a collaborative learning environment. This cooperative environment made them more willing to participate in the study. With the support of BYOD, students thought they could get easy access to necessary information and they felt they could have control over the whole learning process. In addition, through the Python Word-cloud database, the reasons for students' engagement motivation are shown in Fig. 5. The words of cooperation, communication, reflection, innovation, autonomous and friendship appeared with high frequency. This means that with the application of BYOD, students thought they could collaborate and communicate with others, reflect, and promote innovation and autonomous learning, which motivated them to participate in the discussion frequently. Most of the students thought their ability of cooperation was highly improved and they enhanced their friendships through the BYOD support. All of these experiences promoted students' engagement in learning.

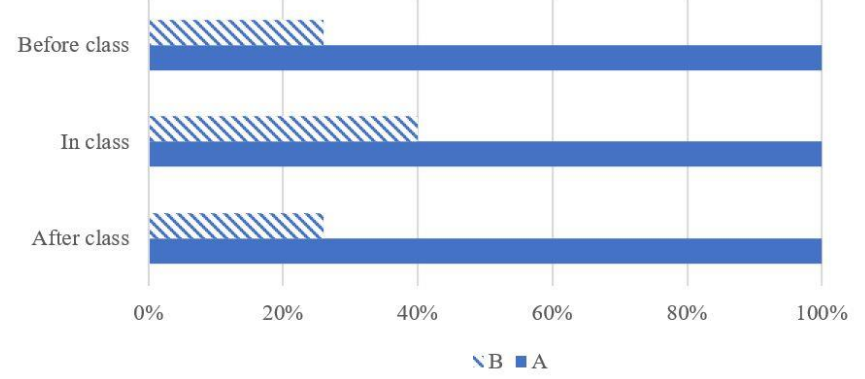

Fig. 4. The percentage of course discussion.

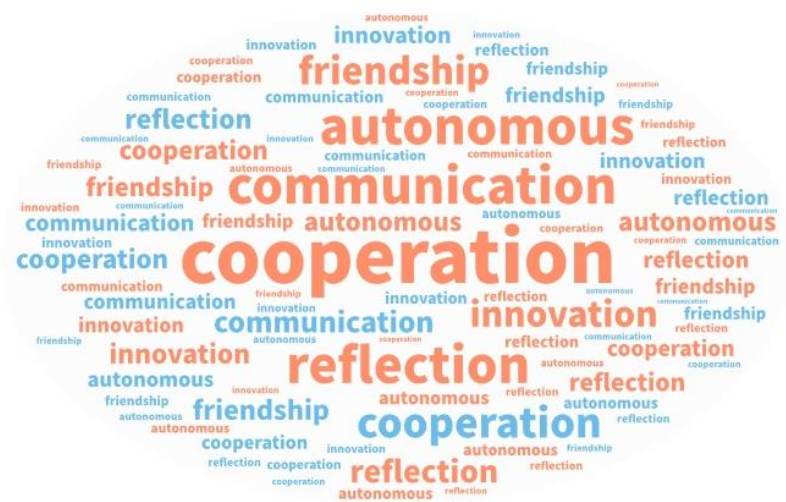

Fig. 5. The word-cloud of abilities

\section{Discussion AND CONCLUSION}

\section{A. Improve the Learning Engagement}

If implementing BYOD in the classroom presents positive learning behaviors, then the research should be considered successful [16]. According to the comparative data from this study, the students' engagement in Course A was significantly higher than in Course B. BYOD to the classroom improved students' motivations for learning engagement. Most students admitted that the application of BYOD in the classroom could obviously stimulate learning interest and arouse enthusiasm. BYOD in the blended learning classroom became a powerful approach for the autonomous and collaborative learning activities such as 
discuss, share viewpoints, and read the links of related resources. In terms of learning engagement, the present study also found that the frequency of visits was relatively high on the day before the face-to-face classroom date. The result was supported by Primana, Indrasari, and Santi (2019), they found BYOD has some essential meaning in learning to make students intrinsically engaged. Therefore, this study suggested that instructors could arrange learning activities on that day to make full use of students' learning enthusiasm and promote their meaning in learning.

\section{B. Promoting Learning Outside the Classroom}

BYOD is one way to extend the place and time of learning and can bridge learning in school, after school, and in the home environment (Stork \& Garabedian, 2018). Outside the classroom, a great number of students in Course A started to use their electronic equipment to access more learning resources and to discuss and solve problems about topics in the curriculum. On their platform, they quickly reacted to an invitation from the teacher to share resources online and comment on the content of the topics. The students in Course $\mathrm{B}$ were asked to do the same learning activities, but they were obviously reluctant to do it. In addition, the outside classroom interaction of students in Course A was higher than that in Course B. Therefore, BYOD could promote students to use their devices for learning outside the classroom and thus fully expand the learning space.

\section{Limitation and Future Study}

Effective integration of BYOD and blended learning can significantly improve students' learning engagement and promote learning outside the classroom. This study provides significance guide for instructor to develop BYOD and blended teaching better. With the popularity of mobile intelligent terminals, BYOD in the classroom is expected to become a popular instructional strategy, especially in undergraduates' blended learning. Further studies examining the BYOD approach should consider the research limitations inherent in this study. First, the Chaoxing learning platform used in this study was fully appropriate for the instructional scenario; however, future studies may employ other available assessment applications (e.g., the Rain classroom) to obtain student learning performance. Different learning applications may create a different learning experience and outcomes. Second, because BYOD instruction and traditional instruction both support student learning, schools should explore ways to integrate these two effective instructional approaches. Finally, due to the limitations of time and space, not all course content could be completed in the classroom instruction. Students' own devices were not limited to the classroom. How to use BYOD to combine the classroom and outside classroom learning should be further studied.

\section{CONFLICT OF INTEREST}

The authors declare no conflict of interest.

\section{AUTHOR CONTRIBUTIONS}

Li Zhao conducted the research; Wei He analyzed the data; Wei He wrote the original draft; Li Zhao reviewed and edited the final paper; all authors had approved the final version.

\section{ACKNOWLEDGMENT}

This research was supported in part by a grant from Social Science Fund of Jiangsu (No.19JYB017); the Collaborative Innovation Center for Talent Cultivating Mode in Basic Education; and the Priority Academic Program Development of Jiangsu Higher Education Institutions in China.

\section{REFERENCES}

[1] S. Ortiz and M. Green, "Trends and patterns of mobile learning: A study of mobile learning management system access," Turkish Online Journal of Distance Education, vol. 20, pp. 161-176, 2019.

[2] J. D. E. Bransford, A. L. E. Brown, and R. R. E. Cooking, "How people learn: Mind, brain, experience and school, expanded edition," National Academy Press, pp. 131-132, 2000.

[3] L. Liu, K. Liu, and J. Zhao, "Development of a model for blended learning based on BYOD: A case study," International Proceedings of Educational Innovation through Technology, pp. 16-22, 2018.

[4] N. Ruxwana, M. Msibi, and T. Mahlangu, "Bring your own device adoption readiness in a South African university," South African Review of Sociology, vol.49, pp.78-95, 2018.

[5] S. C. Kong and Y. Song, "An experience of personalized learning hub initiative embedding BYOD for reflective engagement in higher education," Computers \& Education, vol.88, pp.227-240, 2015.

[6] A. A. Al-Qahtani and S. E. Higgins, "Effects of traditional, blended and e-learning on students' achievement in higher education," Journal of Computer Assisted Learning, vol. 29, pp. 220-234, 2013.

[7] S. A. Becker, M. Cummins, A. Davis, A. Freeman, S. G. Hall, and V. Ananthanarayanan, "NMC horizon report: 2017 higher education edition," The New Media Consortium, pp.1-60, 2017.

[8] M. Pegrum, G. Oakley, and R. Faulkner, "Schools going mobile: A study of the adoption of mobile handheld technologies in Western Australian independent schools," Australasian Journal of Educational Technology, vol. 29, pp. 66-81, 2013.

[9] R. S. Baragash and H. Al-Samarraie, "Blended learning: Investigating the influence of engagement in multiple learning delivery modes on students' performance," Telematics and Informatics, vol. 35, pp. 2082-2098, 2013.

[10] R. Castro, "Blended learning in higher education: Trends and capabilities," Education and Information Technologies, vol. 24, pp. 2523-2546, 2019.

[11] Y. J. Song and Y. Wen, "Integrating various apps on BYOD (Bring Your Own Device) into seamless inquiry-based learning to enhance primary students' science learning," Journal of Science Education and Technology, vol. 27, pp. 165-176, 2018.

[12] A. Zohri and L. Laghzaoui, "Using BYOD instruction to maximize students' engagement and enhance ESL acquisition," International Proceedings on Education and New Learning Technologies, pp. 2490-2498, 2018.

[13] J. M. Pima, M. Odetayo, R. Iqbal, and E. Sedoyeka, "A thematic review of blended learning in higher education," International Journal of Mobile and Blended Learning (IJMBL), vol.10, pp.1-11, 2018.

[14] M. S. Doargajudhur and P. Dell, "Impact of BYOD on organizational commitment: An empirical investigation," Information Technology \& People, vol.32, pp. 246-268, 2019.

[15] M. Olalere, M. T. Abdullah, R. Mahmod, and A. Abdullah, "A review of bring your own device on security issues," Sage Open, vol. 5, pp. 1-11, 2015.

[16] M. Vanwelsenaers, "Students using their own technology device in the classroom: Can "BYOD" increase motivation and learning," M.S. thesis, Dept. Electron. Eng., Northern Michigan Univ, Marquette, USA, 2012.

[17] M. B. W. Kobus, P. Rietveld, and J. N. Van Ommeren, "Ownership versus on-campus use of mobile IT devices by university students," Computers \& Education, vol.68, pp.29-41, 2013.

[18] Y. Song, “"Bring Your Own Device (BYOD)” for seamless science inquiry in a primary school," Computers \& Education, vol. 74, pp. 50-60, 2014

[19] Y. T. Sung, K. E. Chang, and T. C. Liu, "The effects of integrating mobile devices with teaching and learning on students' learning performance: A meta-analysis and research synthesis," Computers \& Education, vol. 94, pp. 252-275, 2016.

[20] N. Ruxwana and M. Msibi, "A South African university's readiness assessment for bringing your own device for teaching and learning," South African Journal of Information Management, vol. 20, pp. 1-6, 2018. 
[21] I. E. Allen and J. Seaman, "Growing by degrees: Online education in the United States," Sloan Consortium, vol.9, pp.1984-1985, 2005.

[22] H. T. Hung, "Clickers in the flipped classroom: Bring your own device (BYOD) to promote student learning," Interactive Learning Environments, vol.25, pp.983-995, 2017.

[23] S. C. Brofferio, "A university distance lesson system: experiments, services, and future developments," IEEE Transactions on Education, vol. 41, pp. 17-24, 1998.

[24] S. Pete, "Blended learning," Elt Journal, vol. 64, pp. 456-458, 2010.

[25] K. Buckley, "Blended learning-how to create an effective course," International Proceedings on Education and New Learning Technologies, pp. 3929-3934, 2016.

[26] F. R. Benbunan, "Blended learning in higher education: Framework, principles, and guidelines, by D. Randy Garrison; Norman D. Vaughan," Academy of Management Learning \& Education, vol. 7, pp. 135-137, 2011.

[27] P. J. Marco, O. Michael, I. Rahat, and S. Eliamani, "A thematic review of blended learning in higher education," International Journal of Mobile and Blended Learning, vol.10, pp.1-11, 2018.

[28] J. Ma, J. Cheng, and X. Han, "Initial development process of a student engagement scale in blended learning environment," International Proceedings of Educational Innovation through Technology, pp. 234-237, 2018

[29] K. A. Smith, S. D. Sheppard, D. W. Johnson, and R. T. Johnson, "Pedagogies of engagement: Classroom-based practices," Journal of Engineering Education, vol. 94, pp. 87-101, 2005.

[30] K. N. Chee, N. Yahaya, N. H. Ibrahim, and M. N. Hasan, "Review of mobile learning trends 2010-2015: A meta-analysis," Journal of Educational Technology \& Society, vol.20, pp.113-126, 2017.

[31] J. S. Cho and Y. M. Jeon, "A case study on effect analysis of students' engagement and learning outcomes in higher education," The Journal of the Korea Contents Association, vol. 19, pp. 524-534, 2019.

[32] L. H. Nian, J. Wei, and C. B. Yin, "The promotion role of mobile online education platform in students' self-learning," International Journal of Continuing Engineering Education and Life Long Learning, vol. 29, pp. $56-71,2019$

[33] D. R. Serrano, M. A. Dea-Ayuela, E. Gonzalez-Burgos, A. Serrano-Gil, and A. Lalatsa, "Technology-enhanced learning in higher education: How to enhance student engagement through blended learning," European Journal of Education, vol. 34, pp. 407-439, 2019.

[34] R. Osborne, E. Dunne, and P. Farrand, "Integrating technologies into "authentic" assessment design: An affordances approach," Research in Learning Technology, vol.21, pp.18, 2013.

[35] M. Pegrum, G. Oakley, and R. Faulkner, "Schools going mobile: A study of the adoption of mobile handheld technologies in Western Australian independent schools," Australasian Journal of Educational Technology, vol. 29, pp. 66-81, 2013.

[36] K.K. Siraj and A. M. Azzah, "Student engagement in blended learning instructional design: An analytical study," Learning and Teaching in Higher Education: Gulf Perspectives, vol.15, 2018.
[37] J. A. Fredricks, P. C. Blumenfeld, and A. H. Paris, "School engagement: Potential of the concept, state of the evidence," Review of Educational Research, vol. 74, pp. 59-109, 2004

[38] B. McMahon and J. P. and Portelli, "Engagement for what? Beyond popular discourses of student engagement," Leadership and Policy in Schools, vol. 3, pp. 59-76, 2004

[39] J. S. Cho and Y. M. Jeon, "A case study on effect analysis of students' engagement and learning outcomes in higher education," The Journal of the Korea Contents Association, vol. 19, pp. 524-534, 2019.

[40] E. R. Kahu, "Framing student engagement in higher education," Studies in Higher Education, vol. 38, pp. 758-773, 2013.

[41] R. Kim, "A longitudinal analysis of the relationship between student engagement and outcome in higher education," Asian Journal of Education, vol. 20, pp. 199-218, 2019.

[42] C. E. Schaeffer and G. D. Konetes, "Impact of learner engagement on attrition rates and student success in online learning," International Journal of Instructional Technology \& Distance Learning, vol. 7, pp. $3-9,2010$.

[43] K. K. Kwon, Chung, and H. Y. Mi, "An analysis of relationship among academic self-efficacy, task value, learning engagement, academic achievement and learning satisfaction in the flipped learning environment," Journal of Educational Technology, vol. 34, pp. 407-439, 2018.

[44] Ü. Avcı and E. Ergün, "Online students' LMS activities and their effect on engagement, information literacy and academic performance," Interactive Learning Environments, pp. 1-14, 2019.

[45] S. Jolly, "Applying technology to enhance student satisfaction and engagement: Case of business students," Tem Journal-Technology Education Management Informatics, vol. 8, pp. 623-629, 2019.

[46] E. A. Skinner and M. J. Belmont, "Motivation in the classroom Reciprocal effects of teacher behavior and student engagement across the school year," Journal of Educational Psychology, vol. 85, p. 571, 1993.

Copyright $\odot 2020$ by the authors. This is an open access article distributed under the Creative Commons Attribution License which permits unrestricted use, distribution, and reproduction in any medium, provided the original work is properly cited (CC BY 4.0).

Wei He was born in Fengcheng, China, on Aug. 19, 1995. She is graduate Student, School of Education Science, Nanjing Normal University. Nanjing, China. She was an undergraduate student at Jiangxi Normal University from 2015 to 2019 and earned her bachelor degree in 2019. Now she is an graduate students at Nanjing Normal University.

Li Zhao was born in Nanjing, China, on June 7, 1982. She is Ph. D, School of Education Science, Nanjing Normal University, Nanjing, China, 2015. She is an associate professor, educational technology, School of Education Science, Nanjing Normal University, Nanjing, China. 